\title{
Adverse Effects of Immune Checkpoint Inhibitors (Programmed Death-1 Inhibitors and Cytotoxic T-Lymphocyte-Associated Protein-4 Inhibitors): Results of a Retrospective Study
}

\author{
Ravneet Bajwa ${ }^{\mathrm{a}}$, Anmol Cheema ${ }^{\mathrm{a}}$, Taimoor Khan ${ }^{\mathrm{a}}$, Alireza Amirpour ${ }^{\mathrm{a}}$, Anju Paul ${ }^{\mathrm{a}}$, \\ Saira Chaughtai ${ }^{a}$, Shrinil Patel ${ }^{a}$, Tejas Patel ${ }^{\mathrm{a}}$, Joshua Bramson ${ }^{\mathrm{a}}$, Varsha Gupta ${ }^{\mathrm{a}, \mathrm{c}}$, \\ Michael Levitt ${ }^{b}$, Arif Asif ${ }^{a}$, Mohammad A. Hossain ${ }^{a}$
}

\begin{abstract}
In recent years the use of immunomodulating therapy to treat various cancers has been on the rise. Three checkpoint inhibitors have been approved by the Food and Drug Administration (ipilimumab, pembrolizumab and nivolumab). The use of these drugs comes with serious adverse events related to excessive immune activation, collectively known as immune-related adverse events (irAEs). We conducted a system-based review of 139 case reports/case series that have described these adverse events between January 2016 and April 2018, found in the PubMed database. There was a broad spectrum of presentations, doses and checkpoint inhibitors used. The most common check point inhibitor observed in our literature review was nivolumab. The most common adverse effects encountered were colitis (14/139), hepatitis (11/139), adrenocorticotropic hormone insufficiency (12/139), hypothyroidism (7/139), type 1 diabetes (22/139), acute kidney injury (16/139) and myocarditis (10/139). The treatment most commonly consisted of cessation of the immune checkpoint inhibitor, initiation of steroids and supportive therapy. This approach provided a complete resolution in a majority of cases; however, there were many that developed long-term adverse events with deaths reported in a few cases. The endocrine system was the mostly commonly affected with the development of type 1 diabetes mellitus or diabetic ketoacidosis being the most frequently reported adverse events. While immunomodulating therapy is a significant advance in the management of various malignancies, it is capable of serious adverse effects. Because the majority of the cases developed pancreatic dysfunction within five cycles of therapy, in addition to the evaluation
\end{abstract}

Manuscript submitted January 16, 2019, accepted February 13, 2019

aDepartment of Medicine, Jersey Shore University Medical Center, Neptune, NJ, USA

bepartment of Hematology/Oncology, Jersey Shore University Medical Center, Neptune, NJ, USA

${ }^{\mathrm{c} C}$ Corresponding Author: Varsha Gupta, Department of Medicine, Jersey Shore University Medical Center, 1945 State Route 33, Neptune, NJ 07753, USA. Email: Varsha.Gupta@hackensackmeridian.org

doi: https://doi.org/10.14740/jocmr3750 of other systems, pancreatic function should be closely monitored to minimize adverse impact on patients.

Keywords: Immunomodulating therapy; Programmed cell death inhibitors; Ipilimumab; Pembrolizumab; Nivolumab; Immunotherapy side effects

\section{Introduction}

The increased use of immune modulating therapy has advanced our understating of the role of immune system in cancer destruction. Immunotherapy is being increasingly utilized to provide individualized treatment for certain cancers. The majority of tumors have genetic and epigenetic alterations that result in diverse antigen expression that can alter the host immune system response. The immune system has the inherent ability to distinguish self from non-self and can typically mount an attack on the non-self tissue such as cancer cells $[1,2]$. T cells are a part of this system and their activation and interaction with the immune system and non-self tissue are important [3]. This process is regulated by stimulatory, co-stimulatory, and inhibitory (checkpoint) signals [4-6]. In addition, there are multiple immunomodulators that target T-cell activation [7]. Among the most promising approaches for this is the blockade of immune checkpoints [8]. Immune checkpoints are inhibitory pathways that keep the immune system in check in order to maintain selftolerance and prevent autoimmunity $[3,8]$. Immune checkpoint blockade by various immune-modulating therapies ultimately results in immune activation against tumor cells [8].

Thus far, there have been three immunotherapy drugs that have been approved by the Food and Drug Administration (FDA) $[9,10]$. These include ipilimumab, pembrolizumab and nivolumab. Ipilimumab is a monoclonal antibody $(\mathrm{mAb})$ that blocks T-cell activation checkpoint inhibitor called cytotoxic T-lymphocyte antigen 4 (CTLA-4) [9]. Pembrolizumab and nivolumab are immunoglobulin G4 (IgG4) mAb that regulates T-cell activation by blocking programmed cell death protein 1 
(PD-1) [10]. These immunotherapy medications are currently used to treat multiple cancers including melanoma, non-smallcell lung carcinoma (NSCLC), glioblastoma, mesothelioma, large-cell lung cancer and renal cell carcinoma $[2,11,12]$.

Despite impressive survival benefits through the use of immunotherapy in patients with melanoma and NSCLC, its use can be hampered by occurrence of serious adverse events related to excessive immune activation, collectively named as immune-related adverse events (irAEs) [3]. This over-activation can potentially affect multiple organ systems including the gastrointestinal tract, kidneys, nervous system, liver, eyes, skin, pancreas and endocrine system [8-12]. Many of the conditions can be life-threatening calling for discontinuation of treatment, long-term corticosteroids and at times anti-tumor necrosis factor therapy [13].

While isolated case reports have highlighted irAE, a systematic review of these complications is not readily available. In this study, we present the adverse side effects associated with immunotherapy, patient characteristics, possible predisposing factors, presentation, management and clinical outcomes of these irAEs.

\section{Literature Search}

A PubMed and manual bibliography search was performed between January 2016 and April 2018. We have decided to conduct our review between these dates as the most recent FDA approval was received in September 2015 for the combination of ipilimumab and nivolumab in patients with advanced melanoma [9]. This way the timeline would include the use of all the immunomodulators thus avoiding the chance for bias. Broadbased search terms were used such as cancer, adverse or harmful events, checkpoint, and immune therapy to name a few. Screening of eligible publications was carried out independently based on organ system. Keywords used were nivolum$\mathrm{ab}$, pembrolizumab, ipilimumab, adrenal, thyroid, diabetes, gastrointestinal, pancreas, renal, kidney, cardiac, myocarditis, colitis and diabetic ketoacidosis (DKA) to name a few. The abstracts were screened and full text of articles was reviewed. The patients who received FDA-approved checkpoint inhibitors such as ipilimumab, pembrolizumab and nivolumab were considered whether they received the treatment in a clinical trial or as part of standard of care.

We defined irAEs as all adverse events reported after treatment with immune inhibitors, which were not present prior to the initiation of treatment. A wide range of affected organ systems were included, like endocrine, gastrointestinal, pulmonary, cardiac and renal systems. We did not collect irAEs involving dermal, genitourinary, hematopoietic, musculoskeletal or nervous system.

The data gathered from the cases included the immunoinhibitor used, adverse effect, patients' age, dose, presentation, specific lab findings pertinent to the organ system, and the outcome. To evaluate the quality of case reports, we used the guidelines for publishing adverse events recommended by International Society of Pharmacovigilance (ISoP) and International Society for Pharmacoepidemiology (ISPE). The case reports were assessed based on the adequate description of the patient (past medical history, demographics, and laboratory abnormalities), the relevance of the title to reported information, and the description of the adverse event and its outcome. Only original reports were included.

Our study has several limitations. We did not analyze individual patient data and thus this review is subject to the quality of case reports. Many case reports did not include the grading of severity of irAEs, and thus were not reported and analyzed by us.

\section{Literature Review}

There were over 3,000 unique citations generated and initially reviewed. A total of 101 publications were included and reviewed. These publications reported a total of 139 cases in which irAEs were discussed. These cases were broken down based on the presenting/underlying adverse events of the patients. Tables 1-5 summarize adverse events and treatment outcomes of checkpoint blockade therapy as they relate to the gastrointestinal, endocrine, cardiac, pulmonary and renal systems.

\section{Gastrointestinal system}

A total of 46 cases involving the gastrointestinal tract were identified. There were 21 cases involving the luminal digestive tract, 13 involving the liver, six involving the biliary tract and six involving the pancreas (Table 1) [14-52].

\section{Endocrine system}

There were a total of 54 cases of immunomodulators causing adverse effects of the endocrine system. There were 14 cases involving the adrenal gland, 17 cases involving the thyroid, 22 cases involving the pancreas and one case involving the parathyroid. The 54 case reports were reviewed in detail with results shown in Table 2 [53-94].

\section{Cardiac system}

Seventeen cases of cardiac toxicity from immune checkpoint inhibitors were reported in PubMed between January 2016 and April 2018. The cases are illustrated in Table 3 below [95-102].

\section{Pulmonary system}

There were a total of five cases found of immunomodulators adversely affecting the pulmonary system as shown in Table 4 $[103,104,105]$.

\section{Renal system}

A total of 18 renal cases were initially found in the search pa- 
Table 1. Summary of Reported IrAEs Involving Gastrointestinal System: UDCA, ENBD

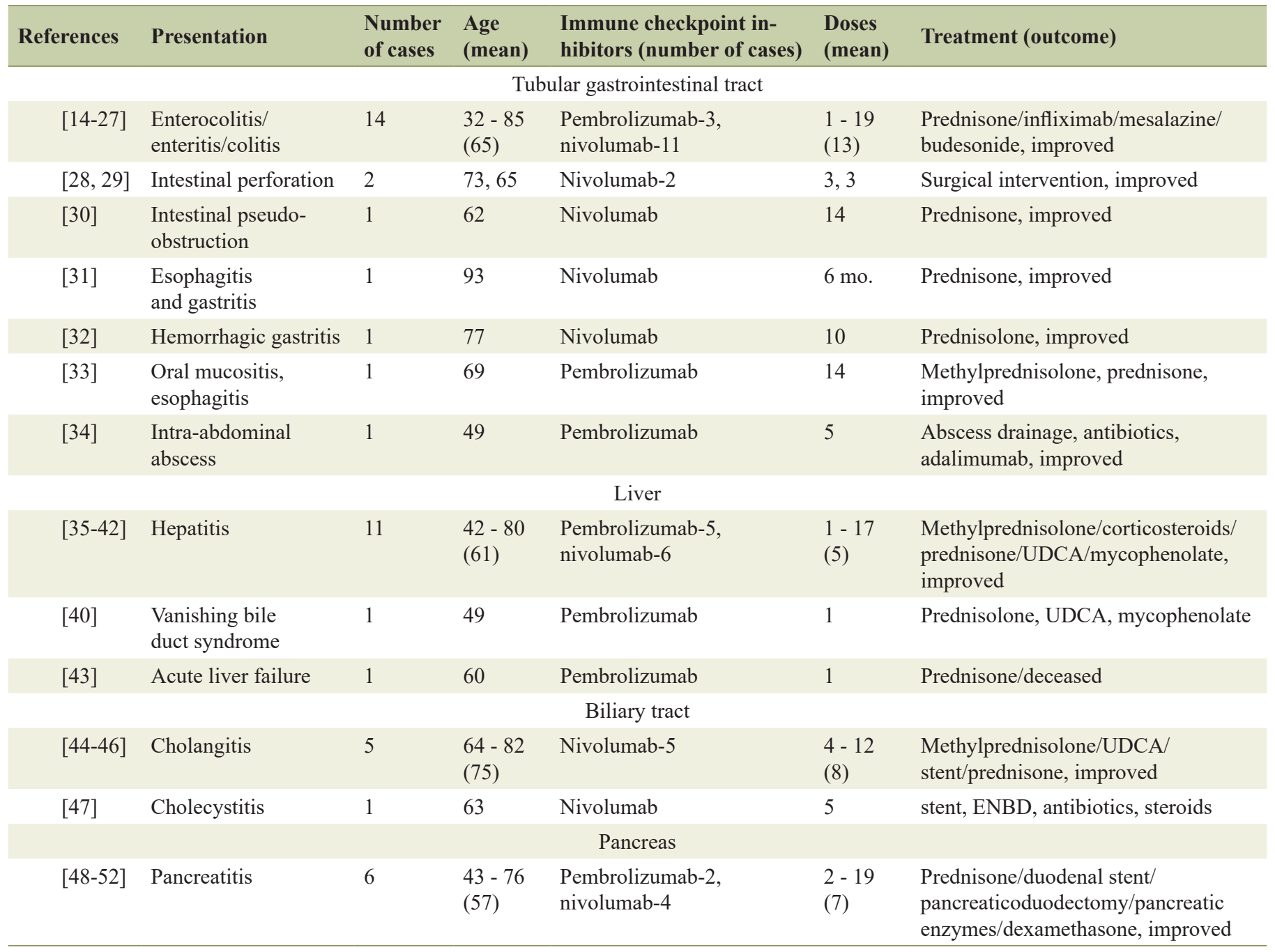

UDCA: ursodeoxycholic acid; ENBD: endoscopic naso-biliary drainage.

rameters outlined in the methods section. One case was discarded from analysis when the renal function improved after discontinuation of proton pump inhibitors. Therefore a total of 17 cases were reviewed. The detailed results are presented in Table 5 [106-113].

\section{Discussion}

With an increased use of immune checkpoint inhibitors it has become more important to understand irAEs and the potential benefit of monitoring patients receiving these therapies. With the advancing interest and research into this new class of medication its use will likely increase in various types of malignancies. While many of the adverse events were well established during the clinical trials, new manifestations are now being reported. Many of the cases report the appearance of autoantibodies; however, the exact mechanism by which immunomodulating therapies induce the development of autoantibodies is not well understood.

\section{Gastrointestinal system}

The incidence of enterocolitis with PD-1 inhibitors can be as high as 30\% [14]. It is important to note that this seemed to occur with as little as one dose of PD-1 inhibitor to as many as 70 doses. Therefore, providers should be tuned into this side effect at any point in the course of therapy. Other gastrointestinal adverse reactions included mucositis, esophagitis, and gastritis with some patients even developing hemorrhagic gastritis (Table 1). Less commonly reported were two cases of intestinal perforation and one case of intestinal pseudo-obstruction. Overall, nivolumab was involved in 16/21 cases, the doses ranged from 1 - 19 and the intervention for the cases consisted of stopping the treatment and administering steroids. Interestingly, there was a reported case of colitis with ipilimumab and secondary switching to pembrolizumab with no resultant 

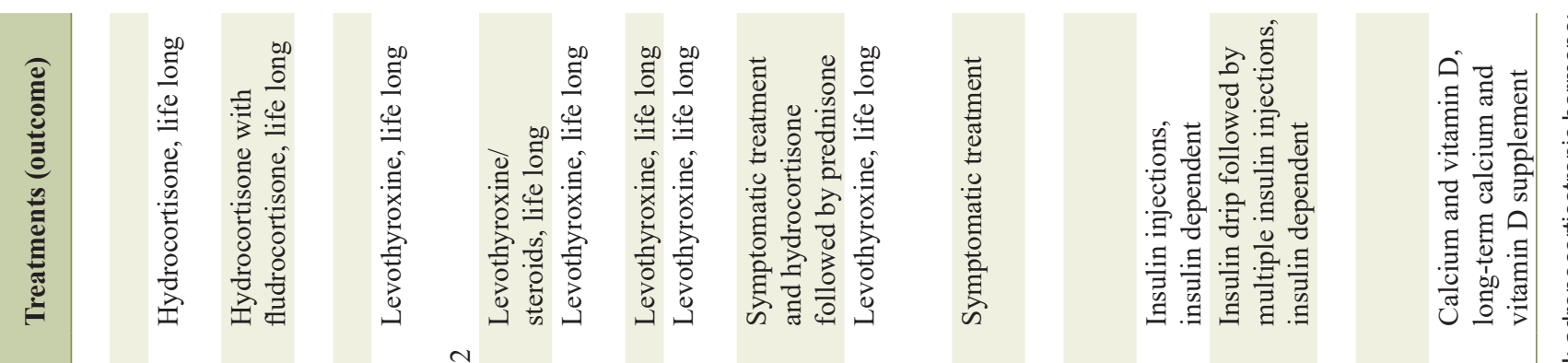

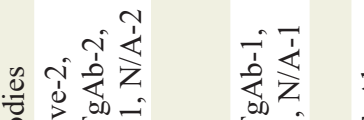

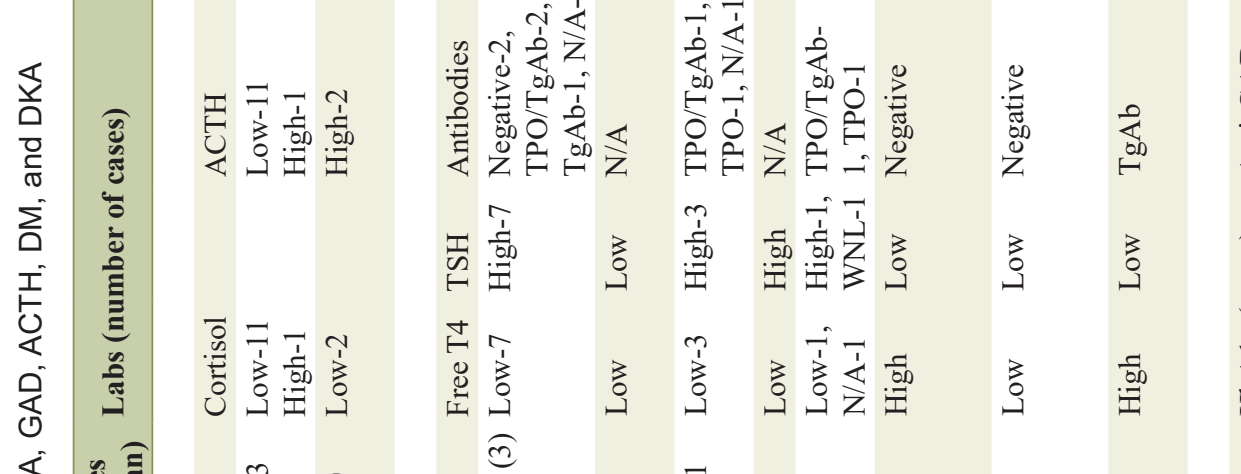

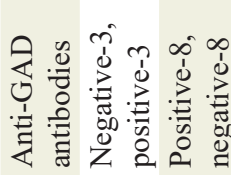
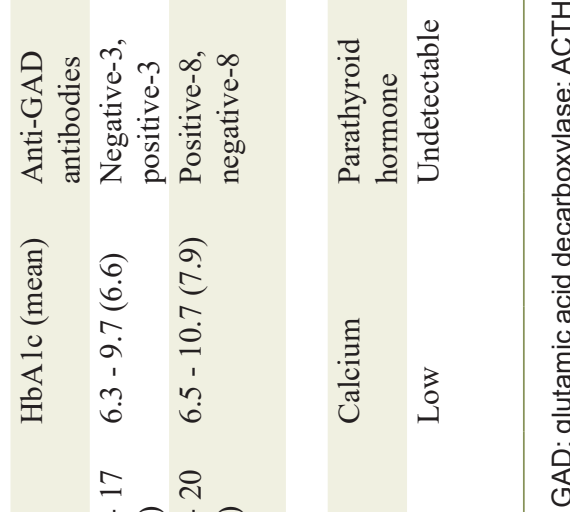

过

(1)

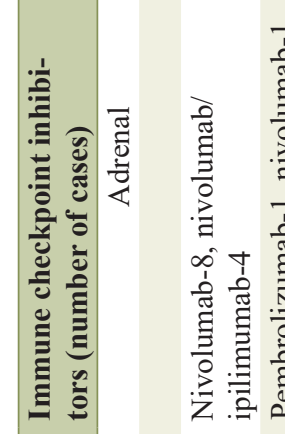

章

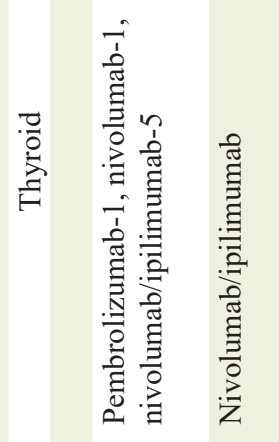

$\bar{n} \cong \ll \vec{z}$

ㅇำ

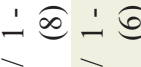

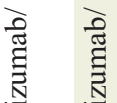

공
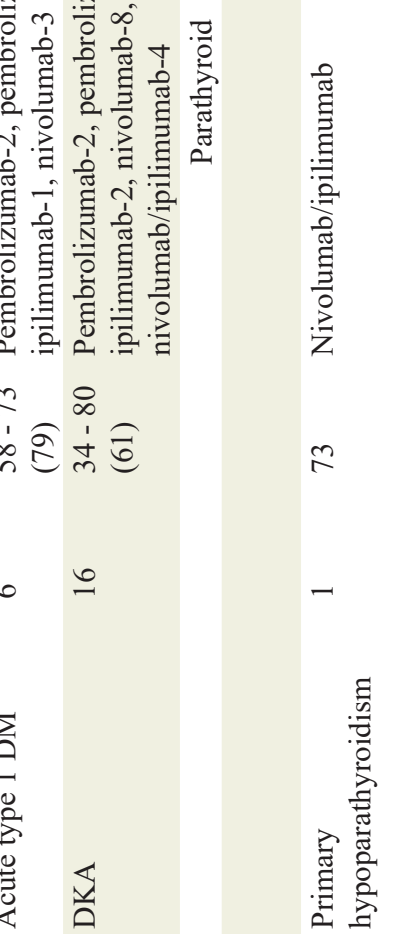

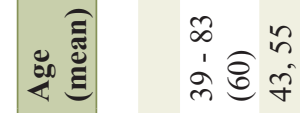

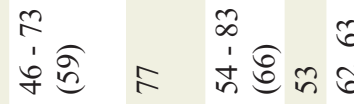

$\stackrel{4}{n}$

$\because \&$

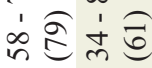
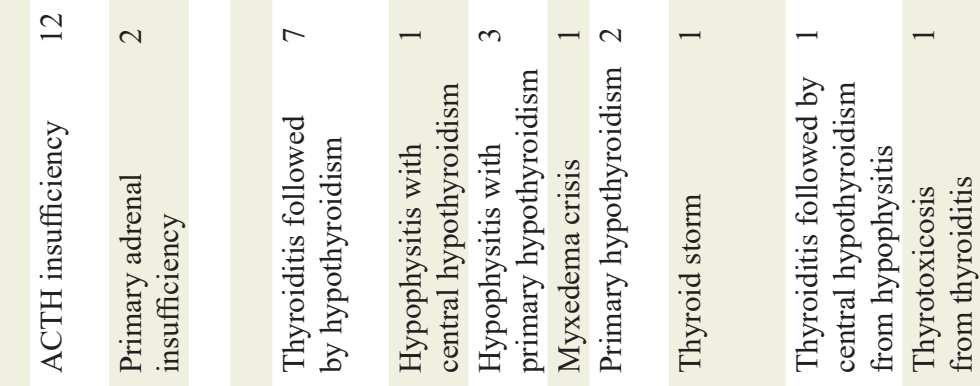

$6 \stackrel{0}{-}$

$\sim \quad \frac{\sqrt{0}}{\frac{0}{\frac{\pi}{\pi}}}$

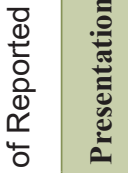

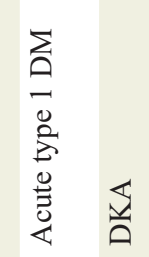

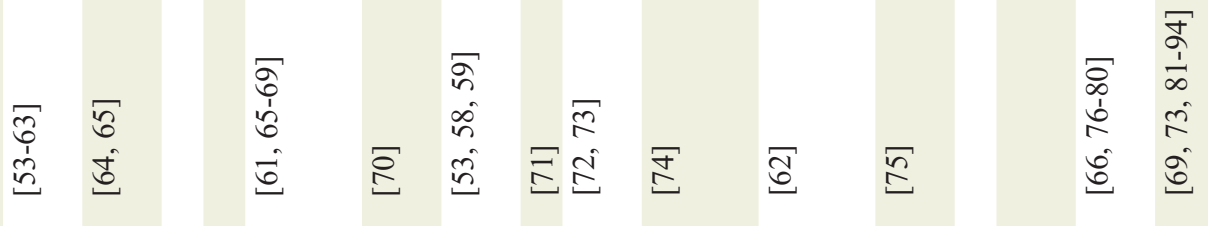



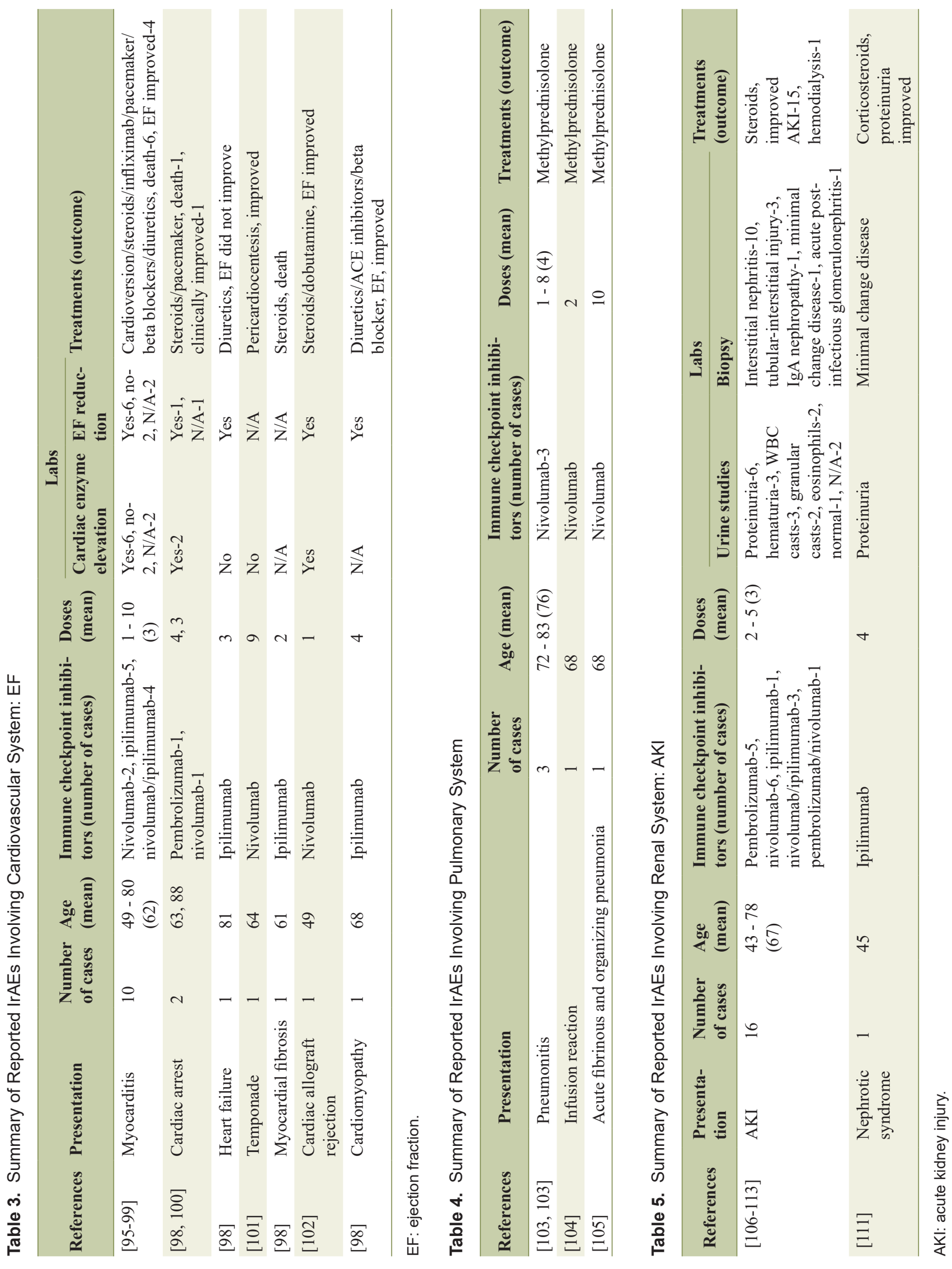
serious toxicities, which indicates that there may be leeway in switching between immunotherapeutic classes, if there is intolerance to one class [15].

There were 13 case reports describing liver injury, which all consisted of hepatitis, with one case of a patient presenting with vanishing bile duct syndrome. The patients all presented with elevated transaminases and the few patients who got a liver biopsy showed non-specific findings such as steatohepatitis, portal inflammation, and/or bile duct injury. The case reports were equally associated with either pembrolizumab or nivolumab, with four of them using a combination of ipilimumab (a CTLA-4 inhibitor). Most cases were reported after only a few doses of PD-1 inhibitor, and many improved with steroids and ursodeoxycholic acid (UDCA) (Table 1).

There were six reported cases of biliary tract abnormalities all comprising of cholangitis, which occurred after four to 12 doses (Table 1). Nivolumab was the only immunomodulator to have caused this reaction with no reported cases of biliary tract dysfunction due to either pembrolizumab or ipilimumab (Table 1). These patients presented with elevated transaminases and computer tomography (CT) scan showing extrahepatic bile duct dilation. Treatment entailed steroids, antibiotics, UDCA and biliary stents in some cases.

There were six reported cases of pancreatitis. The cases were associated with pembrolizumab (two cases) and nivolum$\mathrm{ab}$ (four cases) (Table 1). The treatment for these patients consisted of steroids with a few requiring stents and one requiring a pancreaticoduodenectomy. There was one case report of a patient who developed pancreatic exocrine insufficiency that required life-time pancreatic enzyme replacement therapy [51].

Out of the 46 cases reviewed, the most common adverse effect of the gastroenterology system was enterocolitis $(14 / 46)$ followed by hepatitis (11/46). Nivolumab was the most common immunotherapy seen in this organ system (32/46). The discontinuation of the immunotherapy and prednisone was the most common treatment with the majority of patients having resolution of their symptoms. The side effect of these medications does not seem to be dose-specific as there were cases of adverse events from patients only receiving one dose all the way up to 19 doses.

\section{Endocrine system}

There were a total of 54 cases involving the endocrine system (Table 2). The pancreas was the most common organ to be affected which resulted in either presenting as type 1 diabetes mellitus or DKA (22 cases) followed by thyroiditis (17 cases), primary and secondary adrenal insufficiency (14 cases) and parathyroid dysfunction (one case).

Among the 14 cases of adrenal insufficiency reported in PubMed, 12 of them were associated with nivolumab therapy either alone or in combination with ipilimumab. The patients developed hypophysitis with five of these patients with magnetic resonance imaging images showing pituitary changes. Primary adrenal insufficiency was found in only two out of the 14 cases. The patients were all treated with oral hydrocortisone and/or fludrocortisone as needed with some requiring long-term treatment even after cessation of the drugs.

There were a total of 17 cases of thyroid dysfunction related to immune checkpoint inhibitors (Table 2). There were 13 cases that developed primary hypothyroidism after the development of thyroiditis. Central hypothyroidism due to damage to the adrenal gland and a resultant decrease in thyroid stimulating hormone (TSH) was found in two cases $[62,70]$. Development of thyroid dysfunction mostly within first three doses of PD-1 inhibitor therapy was an interesting and significant finding as in most previously discussed endocrine and gastrointestinal findings there did not seem to be a correlation between doses and occurrence of disease. Out of the 17 cases 12 of them reported on the presence or absence of antithyroid antibodies (Table 2). Out of the 12 cases there were eight cases that were positive for antithyroid antibodies such as thyroid peroxidase (TPO) antibodies and/or thyroglobulin antibodies $(\mathrm{TgAb})$. This shows that although not all of the cases are positive for antithyroid antibodies, the presence of them could help in making the diagnosis. Nivolumab therapy either alone or in combination with ipilimumab was the most common cause for thyroid toxicity (16/17 cases).

There were a total of 22 cases of pancreatic dysfunction in the form of type 1 diabetes mellitus or DKA. There were four patients who presented with acute type 1 diabetes mellitus and two who presented with fulminant type 1 diabetes mellitus. The most common presentation was DKA affecting 16 out of the 22 cases (Table 2). This highlights that the pathophysiology of this immune toxicity is likely acute. DKA as the first presenting symptom should also alert the clinician about the high mortality of this adverse event. Twelve of these 16 cases occurred within the first five cycles of PD-1 therapy, which was a significant finding as this is the only adverse reaction that has shown to be caused consistently by low doses. Twelve of these 16 patients were on nivolumab therapy either alone $(8 / 12)$ or in combination with ipilimumab (4/12). Pembrolizumab was the treatment regimen in four of these cases with two of the four cases on combination therapy with ipilimumab.

A single case of parathyroid dysfunction was reported on nivolumab/ipilimumab combination therapy after two doses. The patient presented with low calcium and an undetectable parathyroid hormone (PTH) level. The patient was started on calcium and vitamin D supplements.

Overall, multiple endocrine adverse effects were noted with immunomodulating therapy. Clinicians must be tuned into these adverse events in order to minimize morbidity and mortality.

\section{Cardiovascular system}

Cardiac toxicities were mainly related to myocardium and electrical conduction system amongst all reported cases (Table 3). Clinical presentation is variable and includes heart failure, atrio-ventricular nodal conduction abnormalities and other arrhythmia. Cardiac adverse effect from immune checkpoint inhibitors is rare but it could be severe. Out of 17 reported cases six patients died mainly secondary to cardiac arrest due to ventricular tachycardia and ventricular fibrillation $[95,96$, 
98, 100]. The timing from the start of the medication to the development of cardiac toxicities was variable ranging from 12 days to 31 weeks, although the two patients who received combination immune checkpoint inhibitors, ipilimumab and nivolumab, developed fatal cardiac arrhythmia within two weeks of treatment $[96,99]$. Nine cases have shown elevated troponin level $[96,98]$. Out of them three patients had ST changes, which include ST depression in two patients and ST elevation in one patient $[96,98]$. Coronary angiography was done which ruled out coronary artery disease with ST segment changes in one patient and remaining two had endomyocardial biopsy, which showed myocarditis. Of the 12 cases that reported ejection fraction there were 10 which showed decreased ejection fraction compared to baseline before immunotherapy as seen on transthoracic echocardiogram.

Corticosteroids were given most commonly for the management strategy. However, corticosteroid use for management has not demonstrated a complete efficacy as four out of 10 patients who had fatal adverse effect were given corticosteroids early in the treatment and showed benefit. The other four did not improve as steroid therapy was delayed. Corticosteroids helped to improve autoimmune myocarditis; however, duration of treatment is unknown. Journal of Immunotherapy reported a case of smoldering myocarditis [114]. The patient received corticosteroids early in the management and tapered over a month but still it was not fully effective [99].

The exact pathophysiology to cause adverse cardiac events is unknown. A recently published animal (mouse model) study demonstrated a critical role of PD-L1 in controlling autoimmune heart and lung diseases [114]. Another study published in Nature Medicine reported that mice deficient in the PD-1 immuno-inhibitory co-receptor develop autoimmune dilated cardiomyopathy with production of high titer autoantibodies against a heart specific protein [115]. Finally, another study revealed that $\mathrm{PD}-1$ deficiency results in development of fatal myocarditis in mice [116]. In this study a biopsy of the myocardium was performed which showed diffuse infiltration of $\mathrm{CD}^{+}$and $\mathrm{CD}^{+} \mathrm{T}$ cells and myeloid cells and there was a high titer of auto-antibodies against cardiac myosin [116]. CTLA-4 ablation also enhances cardio-pathogenicity reported in study published in circulation research with research showing that PD-1, PD-L1 and CTLA-4 play a role in preventing autoimmune myocarditis [117].

Cardiac events are the source of morbidity and mortality. More research is needed to develop prevention protocol to avoid life-threatening cardiac adverse events with use of immune check point inhibitors. Troponin was studied as a biomarker of cardiac damage to predict myocarditis yet the efficacy of troponin is not yet proven [118].

\section{Pulmonary system}

The development of interstitial lung disease (ILD) was mostly observed after the first few rounds of PD-1 inhibitor treatment (Table 4). Interestingly the patients affected in all the cases reported were of Japanese descent although the reason for this is unknown. The mechanisms of toxicity include infusion-related reaction, immune-related adverse reaction and immunosup- pression. It encompasses non-specific interstitial pneumonia, organizing pneumonia, diffuse alveolar damage and acute fibrinous organizing pneumonia. Management depended on the pathophysiology of pulmonary involvement; it included stopping infusions, routine laboratory, radiology, bronchoscopy, lung cultures and autoimmune serology. Steroids are mainstay for treatment of ILDs, which showed good response in all of the patients.

\section{Renal system}

Out of the 18 cases found of renal dysfunction as a result of checkpoint blockade therapy the most common side effect seen was acute interstitial nephritis, which responded well to treatment with steroids and discontinuation of the drugs (Table 5). Minimal change disease was noted in two out of 17 cases, one of which was due to PD-1 inhibitor, and the other a CTLA-4 inhibitor, both of which improved significantly with holding medication and treatment with steroids.

Immunoglobulin A (IgA) nephropathy was noted in one case on treatment with PD-1 inhibitor therapy, which again responded to holding medication and treatment with steroids. It is important to mention that IgA nephropathy is the most common form of glomerulonephritis worldwide. While IgA nephropathy was reported in conjunction, it might have not been related to immunotherapy and could have been an incidental finding.

\section{Conclusions}

Immune checkpoint inhibitors have recently changed the dynamics for treatment of solid tumors with their use becoming more common in the treatment of various malignancies. We found that these drugs can cause multiple adverse effects that increase morbidity and mortality. Therefore, it is important to have a high index of suspicion for these irAEs, as they can be life-threatening. The diagnosis of these side effects, however, should always be accompanied by an extensive work-up to rule out the more common cause of various diseases before attributing the cause to immune checkpoint inhibitors. These work-ups will be dependent on the patient's symptoms and the organ affected. There are no established criteria for monitoring patients for these adverse events. The use of monitoring potential side effects of the treatments can be conducted on a case-by-case basis.

\section{Statement of Ethics}

The authors have no ethical conflicts to disclose.

\section{Funding}

This project was not supported by any grant or funding agencies. 


\section{Conflict of Interest}

The authors declare that there is no conflict of interest regarding the publication of this paper.

\section{References}

1. Abdel-Wahab N, Shah M, Suarez-Almazor ME. Adverse events associated with immune checkpoint blockade in patients with cancer: a systematic review of case reports. PLoS One. 2016;11(7):e0160221.

2. Faghfuri E, Faramarzi MA, Nikfar S, Abdollahi M. Nivolumab and pembrolizumab as immune-modulating monoclonal antibodies targeting the PD-1 receptor to treat melanoma. Expert Rev Anticancer Ther. 2015;15(9):981993.

3. Chan MM, Kefford RF, Carlino M, Clements A, Manolios N. Arthritis and tenosynovitis associated with the antiPD1 antibody pembrolizumab in metastatic melanoma. J Immunother. 2015;38(1):37-39.

4. Ansari MJ, Salama AD, Chitnis T, Smith RN, Yagita H, Akiba H, Yamazaki T, et al. The programmed death-1 (PD-1) pathway regulates autoimmune diabetes in nonobese diabetic (NOD) mice. J Exp Med. 2003;198(1):6369.

5. Guleria I, Gubbels Bupp M, Dada S, Fife B, Tang Q, Ansari MJ, Trikudanathan S, et al. Mechanisms of PDL1mediated regulation of autoimmune diabetes. Clin Immunol. 2007;125(1):16-25.

6. Harris TJ, Drake CG. Primer on tumor immunology and cancer immunotherapy. J Immunother Cancer. 2013;1:12.

7. Gardner D, Jeffery LE, Sansom DM. Understanding the CD28/CTLA-4 (CD152) pathway and its implications for costimulatory blockade. Am J Transplant. 2014;14(9):1985-1991.

8. Pardoll DM. The blockade of immune checkpoints in cancer immunotherapy. Nat Rev Cancer. 2012;12(4):252264.

9. Turnis ME, Andrews LP, Vignali DA. Inhibitory receptors as targets for cancer immunotherapy. Eur J Immunol. 2015;45(7):1892-1905.

10. Page DB, Postow MA, Callahan MK, Allison JP, Wolchok JD. Immune modulation in cancer with antibodies. Annu Rev Med. 2014;65:185-202.

11. Hodi FS, O'Day SJ, McDermott DF, Weber RW, Sosman JA, Haanen JB, Gonzalez R, et al. Improved survival with ipilimumab in patients with metastatic melanoma. N Engl J Med. 2010;363(8):711-723.

12. Ai M, Curran MA. Immune checkpoint combinations from mouse to man. Cancer Immunol Immunother. 2015;64(7):885-892.

13. Bertrand A, Kostine M, Barnetche T, Truchetet ME, Schaeverbeke T. Immune related adverse events associated with anti-CTLA-4 antibodies: systematic review and meta-analysis. BMC Med. 2015;13:211.

14. Kobayashi T, Takahashi K, Terai S. A case of enteritis induced by nivolumab. Clin Gastroenterol Hepatol. 2018.
15. Yasuda K, Tanaka T, Ishihara S, Otani K, Nishikawa T, Kiyomatsu T, Kawai K, et al. Intestinal perforation after nivolumab immunotherapy for a malignant melanoma: a case report. Surg Case Rep. 2017;3(1):94.

16. Iyoda T, Kurita N, Takada A, Watanabe H, Ando M. Resolution of infliximab-refractory nivolumab-induced acute severe enterocolitis after cyclosporine treatment in a patient with non-small cell lung cancer. Am J Case Rep. 2018; 19:360-364

17. Kubo K, Kato M, Mabe K. Nivolumab-associated colitis mimicking ulcerative colitis. Clin Gastroenterol Hepatol. 2017;15(9):A35-A36.

18. Bergqvist V, Hertervig E, Gedeon P, Kopljar M, Griph H, Kinhult S, Carneiro A, et al. Vedolizumab treatment for immune checkpoint inhibitor-induced enterocolitis. Cancer Immunol Immunother. 2017;66(5):581-592.

19. Yanai S, Nakamura S, Matsumoto T. Nivolumab-induced colitis treated by infliximab. Clin Gastroenterol Hepatol. 2017;15(4):e80-e81.

20. Lankes K, Hundorfean G, Harrer T, Pommer AJ, Agaimy A, Angelovska I, Tajmir-Riahi A, et al. Anti-TNF-refractory colitis after checkpoint inhibitor therapy: Possible role of CMV-mediated immunopathogenesis. Oncoimmunology. 2016;5(6):e1128611.

21. Fukumoto T, Fujiwara S, Tajima S, Tamesada Y, Sakaguchi M, Oka M, Nishigori C. Infliximab for severe colitis associated with nivolumab followed by ipilimumab. J Dermatol. 2018;45(1):e1-e2.

22. Fujii Y, Nishikawa Y, Nomura M, Miyamoto S, Uneno Y, Horimatsu T, Muto M. Readministration of nivolumab after persistent immune-related colitis in a patient with recurrent melanoma. Intern Med. 2018;57(8):1173-1176.

23. Bertha M, Bellaguara E, Kuzel T, Hanauer S. Checkpoint Inhibitor-Induced Colitis: A New Type of Inflammatory Bowel Disease? ACG Case Rep J. 2017;4:e112.

24. Abe K, Nakamura N, Isono A, Toyota H, Arai H, Saito $\mathrm{K}$. Inflammatory bowel disease in an elderly woman after nivolumab administration. Am J Gastroenterol. 2017;112(11):1636.

25. Issa M, Milioglou I. Unusual case of immune-related colitis. BMJ Case Rep. 2017;2017.

26. Baroudjian B, Lourenco N, Pages C, Chami I, Maillet M, Bertheau P, Bagot M, et al. Anti-PD1-induced collagenous colitis in a melanoma patient. Melanoma Res. 2016;26(3):308-311.

27. Takenaka T, Yamazaki K, Miura N, Harada N, Takeo $\mathrm{S}$. Osimertinib reactivated immune-related colitis after treatment with anti-PD1 antibody for non-small cell lung cancer. Invest New Drugs. 2017;35(6):848-850.

28. Yasuda Y, Urata Y, Tohnai R, Ito S, Kawa Y, Kono Y, Hattori Y, et al. Immune-related Colitis Induced by the Longterm Use of Nivolumab in a Patient with Non-small Cell Lung Cancer. Intern Med. 2018;57(9):1269-1272.

29. Zarogoulidis P, Chinelis P, Athanasiadou A, Tsiouda T, Trakada G, Kallianos A, Veletza L, et al. Possible adverse effects of immunotherapy in non-small cell lung cancer; treatment and follow-up of three cases. Respir Med Case Rep. 2017;22:101-105.

30. Fragulidis G, Pantiora E, Michalaki V, Kontis E, Prime- 
tis E, Vezakis A, Polydorou A. Immune-related intestinal pseudo-obstruction associated with nivolumab treatment in a lung cancer patient. J Oncol Pharm Pract. 2019;25(2):487-491.

31. Boike J, Dejulio T. Severe esophagitis and gastritis from nivolumab therapy. ACG Case Rep J. 2017;4:e57.

32. Kobayashi M, Yamaguchi O, Nagata K, Nonaka K, Ryozawa S. Acute hemorrhagic gastritis after nivolumab treatment. Gastrointest Endosc. 2017;86(5):915-916.

33. Acero Brand FZ, Suter N, Adam JP, Faulques B, Maietta A, Soulieres D, Blais N. Severe immune mucositis and esophagitis in metastatic squamous carcinoma of the larynx associated with pembrolizumab. J Immunother Cancer. 2018;6(1):22.

34. Uemura M, Trinh VA, Haymaker C, Jackson N, Kim DW, Allison JP, Sharma P, et al. Selective inhibition of autoimmune exacerbation while preserving the anti-tumor clinical benefit using IL-6 blockade in a patient with advanced melanoma and Crohn's disease: a case report. J Hematol Oncol. 2016;9(1):81.

35. Matsubara T, Nishida T, Higaki Y, Tomita R, Shimakoshi H, Shimoda A, Osugi N, et al. Nivolumab Induces Sustained Liver Injury in a Patient with Malignant Melanoma. Intern Med. 2018;57(12):1789-1792.

36. Spankuch I, Gassenmaier M, Tampouri I, Noor S, Forschner A, Garbe C, Amaral T. Severe hepatitis under combined immunotherapy: Resolution under corticosteroids plus anti-thymocyte immunoglobulins. Eur J Cancer. 2017;81:203-205.

37. Aivazian K, Long GV, Sinclair EC, Kench JG, McKenzie CA. Histopathology of pembrolizumab-induced hepatitis: a case report. Pathology. 2017;49(7):789-792.

38. Imafuku K, Yoshino K, Yamaguchi K, Tsuboi S, Ohara K, Hata H. Successful treatment of sudden hepatitis induced by long-term nivolumab administration. Case Rep Oncol. 2017;10(1):368-371.

39. Forschner A, Schraml C, Pierchalla K, Weide B, Eigentler TK, Lauer UM, Garbe C. Pembrolizumab-induced hepatitis: diagnosis and treatment. J Dtsch Dermatol Ges. 2017;15(9):933-935.

40. Doherty GJ, Duckworth AM, Davies SE, Mells GF, Brais R, Harden SV, Parkinson CA, et al. Severe steroidresistant anti-PD1 T-cell checkpoint inhibitor-induced hepatotoxicity driven by biliary injury. ESMO Open. 2017;2(4):e000268.

41. Simonelli M, Di Tommaso L, Baretti M, Santoro A. Pathological characterization of nivolumab-related liver injury in a patient with glioblastoma. Immunotherapy. 2016;8(12):1363-1369.

42. Furudate S, Fujimura T, Kambayashi Y, Hidaka T, Hashimoto A, Aiba S. Sequential Therapy with Nivolumab Followed by Ipilimumab Induces Complete Response in Metastatic Melanoma of the Lung but with Severe Hepatotoxicities. Case Rep Oncol. 2016;9(3):644-649.

43. Wu Z, Lai L, Li M, Zhang L, Zhang W. Acute liver failure caused by pembrolizumab in a patient with pulmonary metastatic liver cancer: A case report. Medicine (Baltimore). 2017;96(51):e9431.

44. Gelsomino F, Vitale G, D'Errico A, Bertuzzi C, Andreone
P, Ardizzoni A. Nivolumab-induced cholangitic liver disease: a novel form of serious liver injury. Ann Oncol. 2017;28(3):671-672.

45. Gelsomino F, Vitale G, Ardizzoni A. A case of nivolumabrelated cholangitis and literature review: how to look for the right tools for a correct diagnosis of this rare immunerelated adverse event. Invest New Drugs. 2018;36(1):144146.

46. Kawakami H, Tanizaki J, Tanaka K, Haratani K, Hayashi $\mathrm{H}$, Takeda M, Kamata K, et al. Imaging and clinicopathological features of nivolumab-related cholangitis in patients with non-small cell lung cancer. Invest New Drugs. 2017;35(4):529-536.

47. Kashima J, Okuma Y, Shimizuguchi R, Chiba K. Bile duct obstruction in a patient treated with nivolumab as second-line chemotherapy for advanced non-small-cell lung cancer: a case report. Cancer Immunol Immunother. 2018;67(1):61-65.

48. Friedman CF, Clark V, Raikhel AV, Barz T, Shoushtari AN, Momtaz P, Callahan MK, et al. Thinking critically about classifying adverse events: incidence of pancreatitis in patients treated with Nivolumab + Ipilimumab. J Natl Cancer Inst. 2017;109(4):djw260.

49. Ikeuchi K, Okuma Y, Tabata T. Immune-related pancreatitis secondary to nivolumab in a patient with recurrent lung adenocarcinoma: A case report. Lung Cancer. 2016;99:148-150.

50. Rawson RV, Robbins E, Kapoor R, Scolyer RA, Long GV. Recurrent bowel obstruction: unusual presentation of pembrolizumab-induced pancreatitis in annular pancreas. Eur J Cancer. 2017;82:167-170.

51. Koldenhof JJ, Suijkerbuijk KPM. Diarrhoea during checkpoint blockade, not always colitis. Eur J Cancer. 2017;87:216-218.

52. Amin NP, Agarwal M, Zainib M, Simone CB, 2nd. Acute pancreatitis: An unexpected toxicity when combining nivolumab and stereotactic body radiation therapy. Pract Radiat Oncol. 2018;8(4):e234-e238.

53. Zeng MF, Chen LL, Ye HY, Gong W, Zhou LN, Li YM, Zhao XL. Primary hypothyroidism and isolated ACTH deficiency induced by nivolumab therapy: Case report and review. Medicine (Baltimore). 2017;96(44):e8426.

54. Okano Y, Satoh T, Horiguchi K, Toyoda M, Osaki A, Matsumoto S, Tomaru T, et al. Nivolumab-induced hypophysitis in a patient with advanced malignant melanoma. Endocr J. 2016;63(10):905-912.

55. Takaya K, Sonoda M, Fuchigami A, Hiyoshi T. Isolated adrenocorticotropic hormone deficiency caused by nivolumab in a patient with metastatic lung cancer. Intern Med. 2017;56(18):2463-2469.

56. Seki T, Yasuda A, Oki M, Kitajima N, Takagi A, Nakajima N, Miyajima A, et al. Secondary adrenal insufficiency following nivolumab therapy in a patient with metastatic renal cell carcinoma. Tokai J Exp Clin Med. 2017;42(3):115-120.

57. Ohara N, Ohashi K, Fujisaki T, Oda C, Ikeda Y, Yoneoka Y, Hashimoto T, et al. Isolated Adrenocorticotropin Deficiency due to Nivolumab-induced Hypophysitis in a Patient with Advanced Lung Adenocarcinoma: A Case Report 
and Literature Review. Intern Med. 2018;57(4):527-535.

58. Kastrisiou M, Kostadima FL, Kefas A, Zarkavelis G, Kapodistrias N, Ntouvelis E, Petrakis D, et al. Nivolumab-induced hypothyroidism and selective pituitary insufficiency in a patient with lung adenocarcinoma: a case report and review of the literature. ESMO Open. 2017;2(4):e000217.

59. Kuru S, Khan N, Shaaban H. Acute hypophysitis secondary to nivolumab immunotherapy in a patient with metastatic melanoma. Int J Crit Illn Inj Sci. 2017;7(3):177180.

60. Kitajima K, Ashida K, Wada N, Suetsugu R, Takeichi Y, Sakamoto S, Uchi H, et al. Isolated ACTH deficiency probably induced by autoimmune-related mechanism evoked with nivolumab. Jpn J Clin Oncol. 2017;47(5):463-466.

61. Ariyasu H, Inaba H, Ota T, Yamaoka H, Furukawa Y, Iwakura H, Doi N, et al. Thyrotoxicosis and adrenocortical hormone deficiency during immune-checkpoint inhibitor treatment for malignant melanoma. In Vivo. 2018;32(2):345-351.

62. Lupu J, Pages C, Laly P, Delyon J, Laloi M, Petit A, Basset-Seguin N, et al. Transient pituitary ACTH-dependent Cushing syndrome caused by an immune checkpoint inhibitor combination. Melanoma Res. 2017;27(6):649652 .

63. Valecha G, Pant M, Ibrahim U, Atallah JP. Immunotherapy-induced autoimmune hypophysitis. J Oncol Pharm Pract. 2019;25(1):217-220.

64. Trainer H, Hulse P, Higham CE, Trainer P, Lorigan P. Hyponatraemia secondary to nivolumab-induced primary adrenal failure. Endocrinol Diabetes Metab Case Rep. 2016;2016(1):16-0108.

65. Paepegaey AC, Lheure C, Ratour C, Lethielleux G, Clerc J, Bertherat J, Kramkimel N, et al. Polyendocrinopathy resulting from pembrolizumab in a patient with a malignant melanoma. J Endocr Soc. 2017;1(6):646-649.

66. Sakurai K, Niitsuma S, Sato R, Takahashi K, Arihara Z. Painless thyroiditis and fulminant type 1 diabetes mellitus in a patient treated with an immune checkpoint inhibitor, nivolumab. Tohoku J Exp Med. 2018;244(1):33-40.

67. Win MA, Thein KZ, Qdaisat A, Yeung SJ. Acute symptomatic hypocalcemia from immune checkpoint therapy-induced hypoparathyroidism. Am J Emerg Med. 2017;35(7):1039 e1035-1039 e1037.

68. Middlebrooks EH, Westbrook BC, Conry RM. Acute inflammatory thyromegaly following checkpoint inhibition: A new imaging entity? Radiol Case Rep. 2018;13(1):8991.

69. Lowe JR, Perry DJ, Salama AK, Mathews CE, Moss LG, Hanks BA. Genetic risk analysis of a patient with fulminant autoimmune type 1 diabetes mellitus secondary to combination ipilimumab and nivolumab immunotherapy. J Immunother Cancer. 2016;4:89.

70. Chang LS, Yialamas MA. Checkpoint Inhibitor-Associated Hypophysitis. J Gen Intern Med. 2018;33(1):125-127.

71. Khan U, Rizvi H, Sano D, Chiu J, Hadid T. Nivolum$\mathrm{ab}$ induced myxedema crisis. J Immunother Cancer. 2017;5:13.

72. Jotatsu T, Oda K, Yamaguchi Y, Noguchi S, Kawanami T,
Kido T, Satoh M, et al. Immune-mediated thrombocytopenia and hypothyroidism in a lung cancer patient treated with nivolumab. Immunotherapy. 2018;10(2):85-91.

73. Li L, Masood A, Bari S, Yavuz S, Grosbach AB. Autoimmune diabetes and thyroiditis complicating treatment with nivolumab. Case Rep Oncol. 2017;10(1):230-234.

74. McMillen B, Dhillon MS, Yong-Yow S. A rare case of thyroid storm. BMJ Case Rep. 2016;2016:10.1136/bcr2016-214603.

75. Verma I, Modi A, Tripathi H, Agrawal A. Nivolumab causing painless thyroiditis in a patient with adenocarcinoma of the lung. BMJ Case Rep. 2016;2016.

76. Kumagai R, Muramatsu A, Nakajima R, Fujii M, Kaino K, Katakura Y, Okumura N, et al. Acute-onset type 1 diabetes mellitus caused by nivolumab in a patient with advanced pulmonary adenocarcinoma. J Diabetes Investig. 2017;8(6):798-799.

77. Chae YK, Chiec L, Mohindra N, Gentzler R, Patel J, Giles F. A case of pembrolizumab-induced type- 1 diabetes mellitus and discussion of immune checkpoint inhibitorinduced type 1 diabetes. Cancer Immunol Immunother. 2017;66(1):25-32.

78. Smith-Cohn MA, Gill D, Voorhies BN, Agarwal N, Garrido-Laguna I. Case report: pembrolizumab-induced Type 1 diabetes in a patient with metastatic cholangiocarcinoma. Immunotherapy. 2017;9(10):797-804.

79. Hansen E, Sahasrabudhe D, Sievert L. A case report of insulin-dependent diabetes as immune-related toxicity of pembrolizumab: presentation, management and outcome. Cancer Immunol Immunother. 2016;65(6):765-767.

80. Munakata W, Ohashi K, Yamauchi N, Tobinai K. Fulminant type I diabetes mellitus associated with nivolumab in a patient with relapsed classical Hodgkin lymphoma. Int J Hematol. 2017;105(3):383-386.

81. Godwin JL, Jaggi S, Sirisena I, Sharda P, Rao AD, Mehra $\mathrm{R}$, Veloski C. Nivolumab-induced autoimmune diabetes mellitus presenting as diabetic ketoacidosis in a patient with metastatic lung cancer. J Immunother Cancer. 2017;5:40.

82. Okamoto M, Okamoto M, Gotoh K, Masaki T, Ozeki Y, Ando $\mathrm{H}$, Anai M, et al. Fulminant type 1 diabetes mellitus with anti-programmed cell death-1 therapy. J Diabetes Investig. 2016;7(6):915-918.

83. Miyoshi Y, Ogawa O, Oyama Y. Nivolumab, an anti-programmed cell death-1 antibody, induces fulminant type 1 diabetes. Tohoku J Exp Med. 2016;239(2):155-158.

84. Shiba M, Inaba H, Ariyasu H, Kawai S, Inagaki Y, Matsuno S, Iwakura H, et al. Fulminant type 1 diabetes mellitus accompanied by positive conversion of anti-insulin antibody after the administration of Anti-CTLA-4 antibody following the discontinuation of Anti-PD-1 antibody. Intern Med. 2018;57(14):2029-2034.

85. Villarreal J, Townes D, Vrablik M, Ro K. A case of druginduced severe endocrinopathies: what providers in the emergency department need to know. Adv Emerg Nurs J. 2018;40(1):16-20.

86. Aleksova J, Lau PK, Soldatos G, McArthur G. Glucocorticoids did not reverse type 1 diabetes mellitus secondary to pembrolizumab in a patient with metastatic melanoma. 
BMJ Case Rep. 2016;2016.

87. Humayun MA, Poole R. A case of multiple immune toxicities from Ipilimumab and pembrolizumab treatment. Hormones (Athens). 2016;15(2):303-306.

88. Mizab Mellah C, Sanchez Perez M, Santos Rey MD, Hernandez Garcia M. Fulminant type 1 diabetes mellitus associated with pembrolizumab. Endocrinol Diabetes Nutr. 2017;64(5):272-273.

89. Leonardi GC, Oxnard GR, Haas A, Lang JP, Williams JS, Awad MM. Diabetic Ketoacidosis as an Immune-related Adverse Event from Pembrolizumab in Non-Small Cell Lung Cancer. J Immunother. 2017;40(6):249-251.

90. Takahashi A, Tsutsumida A, Namikawa K, Yamazaki N. Fulminant type 1 diabetes associated with nivolumab in a patient with metastatic melanoma. Melanoma Res. 2018;28(2):159-160.

91. Capitao R, Bello C, Fonseca R, Saraiva C. New onset diabetes after nivolumab treatment. BMJ Case Rep. 2018;2018.

92. Changizzadeh PN, Mukkamalla SKR, Armenio VA. Combined checkpoint inhibitor therapy causing diabetic ketoacidosis in metastatic melanoma. J Immunother Cancer. 2017;5(1):97.

93. Gauci ML, Laly P, Vidal-Trecan T, Baroudjian B, Gottlieb J, Madjlessi-Ezra N, Da Meda L, et al. Autoimmune diabetes induced by PD-1 inhibitor-retrospective analysis and pathogenesis: a case report and literature review. Cancer Immunol Immunother. 2017;66(11):1399-1410.

94. Teramoto Y, Nakamura Y, Asami Y, Imamura T, Takahira S, Nemoto M, Sakai G, et al. Case of type 1 diabetes associated with less-dose nivolumab therapy in a melanoma patient. J Dermatol. 2017;44(5):605-606.

95. Matson DR, Accola MA, Rehrauer WM, Corliss RF. Fatal Myocarditis Following Treatment with the PD-1 Inhibitor Nivolumab. J Forensic Sci. 2018;63(3):954-957.

96. Johnson DB, Balko JM, Compton ML, Chalkias S, Gorham J, Xu Y, Hicks M, et al. Fulminant Myocarditis with Combination Immune Checkpoint Blockade. N Engl J Med. 2016;375(18):1749-1755.

97. Semper H, Muehlberg F, Schulz-Menger J, Allewelt M, Grohe C. Drug-induced myocarditis after nivolumab treatment in a patient with PDL1- negative squamous cell carcinoma of the lung. Lung Cancer. 2016;99:117-119.

98. Heinzerling L, Ott PA, Hodi FS, Husain AN, Tajmir-Riahi $\mathrm{A}$, Tawbi $\mathrm{H}$, Pauschinger $\mathrm{M}$, et al. Cardiotoxicity associated with CTLA4 and PD1 blocking immunotherapy. J Immunother Cancer. 2016;4:50.

99. Norwood TG, Westbrook BC, Johnson DB, Litovsky SH, Terry NL, McKee SB, Gertler AS, et al. Smoldering myocarditis following immune checkpoint blockade. J Immunother Cancer. 2017;5(1):91.

100. Behling J, Kaes J, Munzel T, Grabbe S, Loquai C. Newonset third-degree atrioventricular block because of autoimmune-induced myositis under treatment with anti-programmed cell death-1 (nivolumab) for metastatic melanoma. Melanoma Res. 2017;27(2):155-158.

101. Nesfeder J, Elsensohn AN, Thind M, Lennon J, Domsky S. Pericardial effusion with tamponade physiology induced by nivolumab. Int J Cardiol. 2016;222:613-614.
102. Owonikoko TK, Kumar M, Yang S, Kamphorst AO, Pillai RN, Akondy R, Nautiyal V, et al. Cardiac allograft rejection as a complication of PD-1 checkpoint blockade for cancer immunotherapy: a case report. Cancer Immunol Immunother. 2017;66(1):45-50.

103. Kumagai T, Kimura M, Inoue T, Tamiya M, Nishino K, Imamura F. Delayed pseudoprogression of lung adenocarcinoma accompanied with interstitial lung disease during chemotherapy after nivolumab treatment. Thorac Cancer. 2017;8(3):275-277.

104. Ogawara D, Soda H, Ikehara S, Sumiyoshi M, Iwasaki K, Okuno D, Dohtsu Y, et al. Nivolumab infusion reaction manifesting as plantar erythema and pulmonary infiltrate in a lung cancer patient. Thorac Cancer. 2017;8(6):706709 .

105. Ishiwata T, Ebata T, Iwasawa S, Matsushima J, Ota S, Nakatani Y, Tsushima K, et al. Nivolumab-induced Acute Fibrinous and Organizing Pneumonia (AFOP). Intern Med. 2017;56(17):2311-2315.

106. Belliere J, Meyer N, Mazieres J, Ollier S, Boulinguez $\mathrm{S}$, Delas A, Ribes D, et al. Acute interstitial nephritis related to immune checkpoint inhibitors. Br J Cancer. 2016;115(12):1457-1461.

107. Kishi S, Minato M, Saijo A, Murakami N, Tamaki M, Matsuura M, Murakami T, et al. IgA nephropathy after nivolumab therapy for postoperative recurrence of lung squamous cell carcinoma. Intern Med. 2018;57(9):12591263.

108. Bottlaender L, Breton AL, de Laforcade L, Dijoud F, Thomas L, Dalle S. Acute interstitial nephritis after sequential ipilumumab - nivolumab therapy of metastatic melanoma. J Immunother Cancer. 2017;5(1):57.

109. Shirali AC, Perazella MA, Gettinger S. Association of acute interstitial nephritis with programmed cell death 1 inhibitor therapy in lung cancer patients. Am J Kidney Dis. 2016;68(2):287-291.

110. Escandon J, Peacock S, Trabolsi A, Thomas DB, Layka A, Lutzky J. Interstitial nephritis in melanoma patients secondary to PD-1 checkpoint inhibitor. J Immunother Cancer. 2017;5:3.

111. Kitchlu A, Fingrut W, Avila-Casado C, Chan CT, Crump M, Hogg D, Reich HN. Nephrotic Syndrome With Cancer Immunotherapies: A Report of 2 Cases. Am J Kidney Dis. 2017;70(4):581-585.

112. Jung K, Zeng X, Bilusic M. Nivolumab-associated acute glomerulonephritis: a case report and literature review. BMC Nephrol. 2016;17(1):188.

113. Murakami N, Borges TJ, Yamashita M, Riella LV. Severe acute interstitial nephritis after combination immunecheckpoint inhibitor therapy for metastatic melanoma. Clin Kidney J. 2016;9(3):411-417.

114. Lucas JA, Menke J, Rabacal WA, Schoen FJ, Sharpe AH, Kelley VR. Programmed death ligand 1 regulates a critical checkpoint for autoimmune myocarditis and pneumonitis in MRL mice. J Immunol. 2008;181(4):2513-2521.

115. Okazaki T, Tanaka Y, Nishio R, Mitsuiye T, Mizoguchi A, Wang J, Ishida M, et al. Autoantibodies against cardiac troponin I are responsible for dilated cardiomyopathy in PD-1-deficient mice. Nat Med. 2003;9(12):1477-1483. 
116. Wang J, Okazaki IM, Yoshida T, Chikuma S, Kato Y, Nakaki F, Hiai H, et al. PD-1 deficiency results in the development of fatal myocarditis in MRL mice. Int Immunol. 2010;22(6):443-452.

117. Love VA, Grabie N, Duramad P, Stavrakis G, Sharpe A, Lichtman A. CTLA-4 ablation and interleukin-12 driven differentiation synergistically augment cardiac pathogenicity of cytotoxic $\mathrm{T}$ lymphocytes. Circ Res. 2007;101(3):248-257.

118. Sarocchi M, Grossi F, Arboscello E, Bellodi A, Genova C, Dal Bello MG, Rijavec E, et al. Serial troponin for early detection of nivolumab cardiotoxicity in advanced non-small cell lung cancer patients. Oncologist. 2018;23(8):936-942. 